\title{
"Você é o que você compra": uma análise da construção de identidades a partir do consumo de artefatos religiosos
}

\author{
Giovanna Rebeca de Souza Trajano ${ }^{1}$ \\ Noemi Fragoso do Nascimento ${ }^{2}$ \\ Rebeca Larissa Placido da Silva ${ }^{3}$
}

Resumo: O presente artigo tem como objetivo a discussão a respeito do consumismo no meio cristão-evangélico, fazendo-se considerações sobre as mudanças provenientes da pandemia do novo coronavírus e em como ela afetou os hábitos de consumo do nicho analisado. Neste sentido, fez-se um apanhado histórico do desenvolvimento do consumo na sociedade até o presente momento de elaboração deste artigo, bem como a relação do consumo com as construções identitárias dos indivíduos e seu pertencimento em determinados grupos sociais. A partir disso, concluiu-se que os estudos a respeito do tema possuem um enfoque maior na doutrina neopentecostal, sendo interessante um aprofundamento maior do tema sob a perspectiva de outras denominações de bases pentecostais e tradicionais.

Palavras-chave: Consumo. Evangélicos. Identidade. Coronavírus

\section{INTRODUÇÃO}

O consumo está presente desde os primórdios da humanidade, quando o ser humano extraía da natureza os insumos para satisfação de suas necessidades básicas de subsistência, como alimentação e vestimenta, sendo, dessa forma, uma prática que visava a sobrevivência. Ao longo do tempo, com o desenvolvimento de novas técnicas de extração e produção, os seres humanos passaram a adaptar os meios naturais para produção do seu próprio alimento e demais utensílios, como objetos de caça.

1 Graduanda do Curso de Comunicação Social pela Universidade Federal de Pernambuco do Centro Acadêmico do Agreste. E-mail:giovanna_trajano@hotmail.com.

2 Graduanda do Curso de Comunicação Social pela Universidade Federal de Pernambuco do Centro Acadêmico do Agreste. E-mail: noeemifragoso@gmail.com.

3 Graduanda do Curso de Comunicação Social pela Universidade Federal de Pernambuco do Centro Acadêmico do Agreste. E-mail: rebecalarissa2011@outlook.com. 


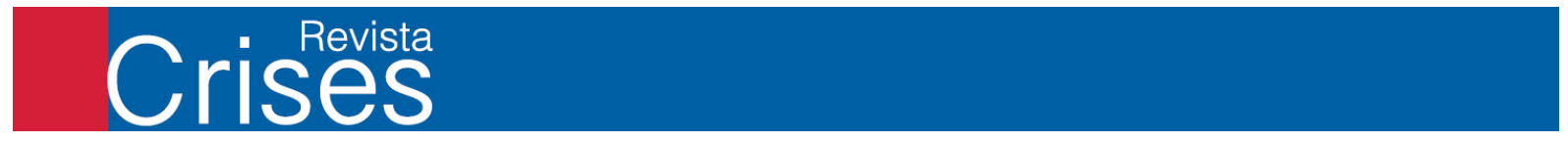

A partir dessa abordagem inicial, é possível perceber o contraste entre as práticas de consumo feitas pelos primeiros seres humanos e as práticas estabelecidas pelo Império Romano (27 a.C e 476 d.C), caracterizadas pelas pré-relações comerciais que, inicialmente, eram mediadas pela troca de produtos ou serviços, até serem feitas, posteriormente, com o uso da moeda, que acabou por sua vez se intensificando com as mudanças dos sistemas político-econômicos da Europa após a queda do feudalismo (XV) e ascensão do capitalismo, sobretudo no período da Revolução Industrial (XVIII), que desencadeou uma produção em massa de bens de consumo, estimulando pessoas ao consumo pelo prazer, e não pela necessidade.

No âmbito do consumo religioso, a separação entre Igreja e Estado teve um papel interessante para o desenvolvimento do consumismo, pois foi determinante para colocar em oposição a magia e a ciência, o sobrenatural e o natural, provocando o que ficou conhecido como "secularização". Para Lima e Trasferetti (2007), o processo de secularização é relativo à perda do controle institucional, jurídico e cultural da sociedade pela Igreja, e, consequentemente, a perda da prerrogativa de construção, imposição e legitimação da sua representação dominante do mundo social.

A distinção entre religioso e secular nasce quando um determinado grupo religioso não conseguiu mais impor suas crenças para toda a sociedade. Portanto, foi necessário que a ordem social passasse a ser organizada de outra maneira que não a religiosa, que estava se mostrando destrutiva. Em função disso, grupos sociais decidiram que para a obtenção da paz, tanto a religião, quanto às controvérsias que a ela diziam respeito, deveriam ser eliminadas. Assim se deu o surgimento do secularismo. Com a clara separação entre Estado e Igreja e com a explicitação de que os códigos que regeriam esses grupos sociais não seriam mais os de um determinado grupo religioso (SILVA, 2018, p. 15-16).

De acordo com Martino (2003), citado por Lima e Trasferetti (2007), com a secularização, o progresso tirou a religião de seu posto hegemônico no mundo. Com o desenvolvimento científico, a crença perdeu seu papel elucidativo, ou seja, sua capacidade de determinação de sentido aos fatos sociais. A religião passou a ser vista como um acessório, possível de ser dispensado para a compreensão do mundo. 


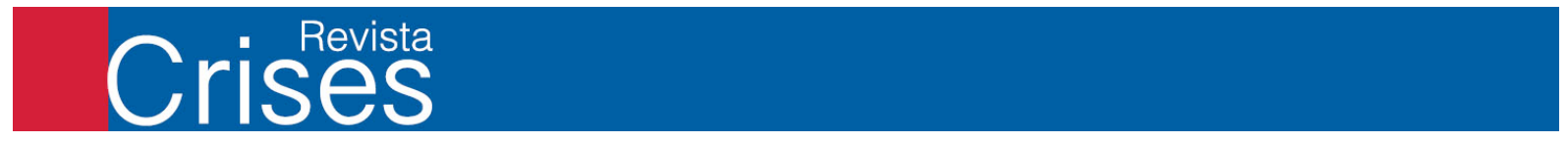

A secularização abriu as portas para o que Weber chamou de "O desencantamento do mundo: a eliminação da magia como meio de salvação" (WEBER, 2004, p. 106, grifo do autor). Com isso, o sujeito passa a se ver sozinho no mundo e Deus está distante demais para ouvi-lo. Esse desencantamento do mundo será o caminho traçado por Max Weber para relacionar a Reforma, o calvinismo e o desenvolvimento do espírito capitalista (SILVA, 2018).

Com a Reforma Protestante (XVI), houve um crescimento do número de evangélicos, em decorrência da conversão de pessoas que anteriormente não professavam nenhuma religião, e também por conta de ex-católicos que decidem converter-se ao protestantismo. Tais conversões trouxeram novas atitudes em relação ao trabalho e ao consumo, pois a Reforma teve um papel crucial para o desenvolvimento da economia e fortalecimento do capitalismo, principalmente na Europa, como aborda Max Weber em seu livro "A ética protestante e o espírito do capitalismo" (1905). Weber afirma que a teologia de Calvino, um dos Reformadores, enfatizava o sucesso financeiro como um sinal da predestinação divina.

A conquista do sucesso advindo do fato de ter sido escolhido por Deus era uma consequência que tornava patente para o grupo social o acerto na opção pelo caminho indicado por Ele, a certeza de se ter sido escolhido era o sucesso profissional como expressão da vocação dada por Deus e seu correto cumprimento. O sucesso obtido para quem se dispusesse a seguir a vocação era proposto através da racionalidade do trabalho, que buscava sempre fazer melhor e mais para a glória de Deus, e que acaba permeando outros aspectos da vida; da concepção de mundo voltada para a Graça Divina, que é reconhecida através do sucesso profissional e financeiro; e de uma vida regrada voltada para o trabalho executado como vocação, chamamento e predestinação (SILVA, 2018, p. 28).

Dessa forma, esbanjar sucesso econômico e prosperidade era visto como um sinal de ter sido escolhido por Deus para receber a salvação. Silva (2018) alerta para esse excesso de trabalho e acúmulo de riquezas como atitudes que fortaleceram ainda mais o "mundo desencantado", controlado por números e quantidades, aliados aos conceitos científicos, que não abrem brecha para os fatos sobrenaturais da religião. A partir disso, 


\section{Crisenges

"a ética protestante passa a ser uma das causas do desenvolvimento do capitalismo, já que oferece os conceitos necessários para o crescimento econômico nas sociedades que o adotam" (SILVA, 2018, p. 28).

Carter Lindberg (2017) contesta a afirmativa de Weber apontando que ao abordar a teologia de Calvino como sendo comunal e não individualista - como trata o sociólogo alemão -, alegando que as riquezas não demonstravam a aprovação de Deus e a salvação do indivíduo, mas sim, a benção de Deus. Contudo, o historiador também compreende a importância da Reforma para o desenvolvimento econômico.

No campo da economia, Lutero e Calvino atacaram vigorosamente o capitalismo como ganância irrestrita, pedindo ao governo para que o controlasse. Por outro lado, Lutero, Zuínglio e Calvino contribuíram para o desenvolvimento do bem-estar social moderno. Programas nacionais e locais de assistência social foram instituídos em resposta às causas estruturais de desemprego e subemprego, à necessidade de formação profissional e responsabilidade civil para a prevenção e redução da pobreza (LINDBERG, 2017, p. 430).

Partindo das premissas delineadas até aqui, o presente artigo terá como foco de análise as práticas de consumo feitas por fiéis cristãos de diferentes denominações evangélicas e em como essas práticas contribuem na construção de identidades e no desejo de pertencimento desses indivíduos nos grupos sociais.

Essas denominações se diferem a partir de suas estruturas organizacionais e suas doutrinas, que são extraídas com base na Bíblia, contudo, são desenvolvidas a partir de visões de mundo e interpretações diferentes. Algumas denominações, por exemplo, não permitem a utilização de calças e adereços como brincos, colares, pulseiras e anéis em mulheres e também não permitem que elas exerçam cargos de liderança na comunidade, se utilizando de textos bíblicos para justificar tais proibições. Outras, permitem até que mulheres sejam pastoras e são menos restritivas no quesito vestimenta. É importante frisar que ambas as visões justificam suas doutrinas com base no mesmo livro, conforme a interpretação de um autor, teólogo ou líder religioso. Elas podem ser categorizadas em basicamente três tipos: tradicionais, pentecostais e neopentecostais. 


\section{REFERENCIAL TEÓRICO}

\subsection{CONSUMO NO MEIO CRISTÃO-EVANGÉLICO}

Ana Beatriz Barbosa Silva (2014) classifica e discorre sobre dois tipos básicos de consumo: consumo primário, que se trata das necessidades de subsistência humana, e o secundário, relacionado à satisfação de desejos criados pelos próprios seres humanos. $\mathrm{O}$ consumo primário é, dessa forma, praticado com a finalidade de garantir os itens básicos e necessários à sobrevivência humana, o mesmo tipo de consumo praticado nos primórdios da humanidade:

O consumo primário está intimamente relacionado à nossa subsistência; ele seria responsável, primordialmente, pela obtenção de comida, abrigo físico e proteção contra outros predadores e intempéries da natureza. [..] o consumo primário é facilmente exercido quando vamos ao supermercado e colocamos no carrinho de compras os alimentos necessários à nossa alimentação, bem como os objetos destinados à nossa higiene pessoal e à manutenção da nossa casa (SILVA, 2014, p.24).

Em contrapartida, o consumo secundário visa a satisfação, não de necessidades vitais e básicas, mas de desejos criados e estimulados tanto pelos mais diversos meios embutidos dentro do Marketing, como a publicidade e propaganda, quanto pelos próprios indivíduos naquilo que constituem para si como fonte de prazer e satisfação.

Tal satisfação tem como finalidade proporcionar a sensação de bem-estar a partir da noção de pertencimento e felicidade ao adquirir bens de consumo. As práticas de consumo classificadas como consumo secundário, também conhecido como consumismo, estão relacionadas, dessa forma, ao exagero, ao excesso, ao impulso. De acordo com Silva (2014, p. 25), "vivemos em um mundo que gira em função do consumo secundário, e é essa forma de consumir que abre as portas do consumismo e da sua vertente patológica".

Dessa forma, o consumo de bens materiais no meio cristão, mais especificamente cristão-evangélico, que é o cerne deste trabalho, pode ser enquadrado no consumo 


\section{Crisen

secundário, sendo caracterizado pela aquisição e utilização em excesso de artefatos religiosos.

Como exemplo, destaca-se a Teologia da Prosperidade, cuja principal ideia é que os indivíduos, uma vez que se convertam, serão abençoados na forma de bens materiais, estimulando assim o consumo e o exibicionismo (SILVA, 2018).

As raízes da Teologia da Prosperidade surgem nos Estados Unidos durante o século XIX, tendo como berço o puritanismo. A consequência da fé estaria intimamente relacionada à doação financeira, a partir dessa doação o indivíduo estaria diante da germinação da sua própria prosperidade. A vertente moderna da TP data do século XX, demarcando o surgimento de sua disseminação por meio dos aparatos midiáticos (LEMOS, 2017, p. 81).

No Brasil, a Teologia da Prosperidade (TP) ganha forma no século XX, com a fundação da Igreja Universal do Reino de Deus (IURD) pelo bispo Edir Macedo, alicerçada a máxima capitalista: acumulação financeira e de patrimônios sem limites (LEMOS, 2017). A manipulação de compra feita pela igreja neopentecostal é mais explícita com a IURD construindo sua própria lógica de consumo, o que acaba gerando um exibicionismo e hedonismo que remete ao tempo da Reforma.

É a propaganda e os meios midiáticos, ao se valerem do princípio da TP para estimular o consumo, que promovem um (re)encantamento com o mundo. O fiel agora tem uma maneira de exibir suas riquezas com artefatos que manifestam a sua fé.

O encantamento surge com a possibilidade de se partilhar do universo do consumo proposto pela propaganda. [...] A religião seria o encantamento de mediação para se chegar às possibilidades de aquisição de mercadorias. Portanto, não seria a religião em si a fonte de reencantamento [...] podemos pensar que a propaganda seja a real fonte de encantamento na vida cotidiana que se verifica no consumo (SILVA, 2018, p. 37).

A vida, que antes era desencantada e fria, agora brilha diante dos olhos. Muitos fiéis passam a buscar o sentido da vida na propaganda e na aquisição de bens e serviços. 




Por isso a oposição entre trabalho frio e consumo encantado. Para que se possa consumir e, finalmente, se encantar com a vida, é que se suporta um cotidiano desencantado (SILVA, 2018).

Nos últimos 20 anos houve um crescimento considerável no número de evangélicos no Brasil. De acordo com os dados do censo do IBGE (CENSO 2010), o grupo representava 15,4\% da população brasileira em 2000 e 22,2\% em 2010, já uma pesquisa publicada pelo Datafolha em 2020 aponta que esse número cresceu para 31\%. Esse crescimento causou, consequentemente, segmentação de congregações ${ }^{4} \mathrm{e}$ denominações, o que gerou novos nichos no mercado e uma adaptação da propaganda para atender a esses diferentes grupos, que mesmo pertencentes a uma mesma religião, passaram a divergir em certos valores, princípios e doutrinas, como em relação à Teologia da Prosperidade. Quanto mais a religião se segmenta, assim como o mercado de consumo material e pagão, mais cresce a demanda, o que consequentemente aumenta a oferta (REFKALEFSKY; PATRIOTA; ROCHA, 2006). Sobre isso, observa-se também que:

Dessa forma, o pluralismo religioso e a variedade dos concorrentes no mercado criam um ambiente propício, e ao mesmo tempo, necessário para o aparecimento das técnicas de marketing, visando conquistar e manter os fiéis, ampliando a diversificação de produtos e serviços religiosos com o firme propósito de atender a demanda do mercado religioso (REFKALEFSKY; PATRIOTA; ROCHA, 2006, p. 5-6).

A religião que, durante muito tempo, ensinou os fiéis a respeito da vida e da morte, com ênfase na vida eterna, na modernidade, tem a sua capacidade de convencimento enfraquecida diante do conhecimento científico. Todavia, ainda se faz presente fortemente na vida dos fiéis (e também de não fiéis), por meio dos artefatos religiosos, que, de acordo com Refkalefsky; Patriota; Rocha (2006), produz seres humanos solitários que tendem a consumir a própria religião (ou a de outro) como uma tentativa de compensar as necessidades afetivas. A partir disso, tem-se então a formação de uma indústria cultural evangélica fortificada e alimentada pela mídia e pelo marketing

4 Congregação: Ramificação de uma determinada igreja que se expande para outros bairros, cidades, etc. O termo "congregação" também pode ser empregado para se referir à um grupo/comunidade de fiéis. 


\section{Criseng

(PAEGLE,2011).

\subsection{A PANDEMIA E O CONSUMO ONLINE}

A infecção pelo vírus SARS-CoV-2 que causa a COVID-19 (do inglês, Coronavirus Disease 2019), modificou drasticamente a estrutura econômica e social mundial. Em função da rápida taxa de transmissão e contaminação e da inexistência de medidas terapêuticas específicas, o que antes era uma epidemia, transformou-se em uma pandemia, alastrando-se por diversos continentes e obrigando muitos países a tomarem medidas rápidas e restritivas.

Como a transmissão do coronavírus ocorre, principalmente, de pessoa para pessoa, por meio de gotículas de saliva, a Organização Mundial da Saúde (OMS) recomendou aos governos medidas que incluem a lavagem das mãos, o uso de máscaras, a restrição social e até mesmo a proibição do funcionamento de espaços onde pode haver aglomeração de pessoas. No Brasil, muitas medidas foram adotadas nos estados e municípios para tentar conter a disseminação do vírus, como o fechamento de escolas e também de comércios considerados não essenciais como lojas, igrejas, restaurantes, etc.

Todo esse controle e cuidados modificaram os hábitos diários dos brasileiros. Com o contato social restrito e o isolamento tornando-se uma realidade cotidiana, muitos passaram a desenvolver suas atividades em casa, como trabalho e lazer, e tiveram seus estilos de vida alterados. Contudo, essas mudanças não se limitaram ao âmbito social, mas perpassa também o âmbito econômico, pois assim como os hábitos mudaram, as relações de consumo das pessoas acompanharam essa transformação.

Uma pesquisa realizada pela Mastercard e Americas Market Intelligence indicou que o distanciamento social fez com que o e-commerce (modalidade de comércio no qual todos os processos relacionados à compra, venda e transações financeiras são feitas via internet) na América Latina e no Caribe fosse impulsionado. A pesquisa apontou que aproximadamente $46 \%$ dos brasileiros aumentaram o volume de compras online durante a pandemia e 7\% compraram online pela primeira vez (ECBR, 2020). 
Esses números são produto da adaptação tanto dos consumidores, quanto das empresas, ao "novo normal" concebido pela pandemia, que resultou na aceleração da digitalização dos negócios e na intensificação do uso de canais digitais de interação com os consumidores.

Assim, avanços esperados para o futuro tiveram de ser antecipados, e essa aceleração digital tornou-se um salto tecnológico onde empresas e pessoas tiveram que dar, para se adaptarem a nova dinâmica imposta pelo novo Coronavírus, no intuito de salvarem seus negócios, e encontrar meios de chegarem até o consumidor (ALVES; BRITO, 2020, p. 9).

As compras online trouxeram novas perspectivas, principalmente para aqueles que nunca haviam feito esse tipo transação, pois se mostrou uma opção mais confortável, prática e segura para os consumidores, que agora poderiam fazer pesquisas de preços e usufruir de suas compras sem sair de casa. As lojas (varejo e atacado), por sua vez, precisaram demandar mais esforços para se destacarem em meio às tantas outras que faziam da internet seu mais novo ponto de venda. Estratégias de Marketing Digital, desenvolvimento de plataformas de e-commerce e utilização de redes sociais foram alguns dos principais passos que os empreendedores tiveram que dar para se manter no mercado.

As igrejas também precisaram se adaptar a esse novo contexto pandêmico. Classificadas como serviço não essencial, muitas tiveram seus cultos e celebrações paralisadas, outras, todavia, decidiram que a internet poderia ser um mediador entre a Palavra e os fiéis. Igrejas mais conhecidas, com ramificações espalhadas pelo país e já fortemente presentes nos meios tradicionais, como a televisão, alavancaram ainda mais seus esforços para se assegurar nos meios digitais, já outras, base mais tradicional e de pequeno porte, decidiram dar seus primeiros passos nesse novo mundo da internet e expandir seus meios de comunicação.

Cultos online, dízimos e ofertas depositados via transferência bancária e pix foram apenas uma pequena parte de todo o aparato digital que a internet possibilitou às igrejas. Algumas delas conseguiram se aproveitar um pouco mais e abriram seus próprios ecommerces, outras aprimoraram as lojas online que já possuíam. Além disso, 


\section{Crisevista

conferências cristãs, que antes, feitas presencialmente, realizavam feiras de vendas de produtos evangélicos, com a pandemia, precisaram reunir todos os produtos em ecommerces.

Entre as redes sociais, o Instagram foi a mais utilizada durante a pandemia, com um total de interações 18,7 vezes maior que o Facebook, de acordo com o estudo feito pela Socialbakers com base nos 50 maiores perfis de marcas no Brasil e no mundo, entres os meses de abril e junho de 2020. Foi percebendo esse aumento que muitas empresas de produtos do nicho evangélico começaram a montar suas lojas dentro do próprio Instagram, com catálogo, preços e links de redirecionamento para páginas de compra.

A partir de todo conteúdo abordado até aqui, veremos, a seguir, como o consumo faz com que os produtos não sejam mais notados com base no seu valor de uso, para atender às necessidades dos indivíduos, mas sim, com base no seu valor simbólico, para satisfazer os desejos criados pela própria indústria.

\subsection{CONSUMO E IDENTIDADE}

O valor simbólico é aquele que está no âmbito do intangível, das ideologias, dos valores e das crenças, uma vez que, o seu sentido não está na materialidade, mas sim, nos significados que ela carrega. O valor simbólico de um produto pode ser percebido no desejo que o consumidor tem em adquiri-lo e/ou na culpa que sente por não ter conseguido.

O mercado é um campo de batalha para as empresas exporem seus produtos, em virtude de uma concorrência acirrada e poucos espaços de grande visibilidade disponíveis. Por isso, o investimento em mídia e marketing é tão valorizado porque são eles os principais agregadores de valor simbólico a um produto, inclusive no mercado evangélico, e serão responsáveis também por dar vazão à produção em larga escala. Para Paegle (2011, p.7) "[...] a intensificação da mercantilização dos bens simbólicos religiosos tem atuado com apoio da mídia e do marketing para alcançar cada vez mais consumidores ávidos em consumir produtos e serviços que respondam às demandas da sua fé". 


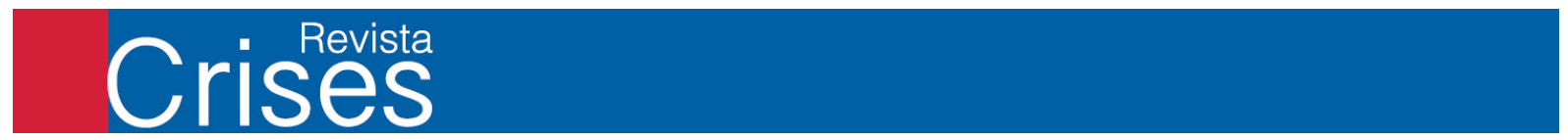

Para que um produto tenha bem mais do que simplesmente atributos pertinentes ao seu valor de uso, é preciso acrescentar a ele valores simbólicos criados pela própria mídia institucionalizada e pela mídia individual, formada pelos consumidores com poder de fala e opinião, que por sua vez, também acabam incentivando a compra e o uso do artefato. Ao emaranhar o produto de valores simbólicos, incentivando o desejo acima da necessidade e o querer acima do dever, tem-se, consequentemente, o estímulo do ter acima do ser.

[...] não sabemos bem quem somos, mas sabemos quanto valemos: somos o carro, a lancha, a casa ou os quadros que temos. A economia capitalista focaliza tudo em torno de cifrões. Em compensação, embaraça tudo o mais. Cada vez nos tornamos mais eficientes, mais baratos e mais produtivos (SAYAD, 1998, p. 14 apud LIMA; TRASFERETTI, 2007, p. 50$51)$.

Os símbolos estão intrinsecamente ligados aos sistemas representativos, que, por sua vez, constituem as identidades. Dessa forma, representação e identidade estão interligadas socialmente e culturalmente por símbolos que serão a base da construção de sentido que se é feita do sujeito, inclusive do evangélico, e das relações ao redor. Woodward (2014) afirma que os sistemas simbólicos tornam possível aquilo que somos e o que podemos nos tornar.

O entendimento que o sujeito tem de si com base nos sistemas simbólicos que adere só é possível de ser percebido e compreendido com relação àquele que difere dele. Woodward (2014) trata da construção das identidades como um processo que é formado relativamente a outras identidades, ao "forasteiro", ao "outro", ao diferente, ou seja, relativamente ao que não é. Esse vínculo entre identidade e diferença também é enfatizado por Silva (2014), que afirma que, mesmo ambas tendo caráter independente, elas ainda estão interligadas no processo de classificação que o indivíduo fará de si, considerando que, a partir do momento em que este afirma ser algo, ele consequentemente está negando ser outra coisa.

No caso dos evangélicos, a adesão de produtos religiosos, está relacionada à construção da autoimagem do sujeito consumidor e ao exibicionismo e ostentação, como 


\section{Crisevista

abordado no caso do consumo no meio neopentecostal, mas também pode ser analisada como necessidade de reafirmação, aceitação e pertencimento, principalmente no que tange a outras denominações, mais tradicionais, por exemplo, e em como o fiel se difere do pagão e dos próprios membros da igreja. Esses fatores podem contribuir para o excesso de consumo e, de acordo com Featherstone (1995, p. 31) apud Paegle (2011, p. 2) "[...] as mercadorias criam vínculos e sinais de pertencimento, [...] os evangélicos também buscam consumir bens simbólicos que exemplificam a sua pertença à comunidade de fé que congregam".

Ao aderir algum produto de sua religião e doutrina, o fiel constitui e reafirma a sua identidade e distinção diante dos outros, para evidenciar a sua fé aos não evangélicos, bem como para ser aceito na igreja que participa e se encaixar em um determinado grupo ou ministério dentro da própria congregação. A construção da identidade do evangélico é, então, simbólica e pautada na incumbência que ele tem em não ser classificado e visto como o "Outro".

\section{CONSIDERAÇÕES FINAIS}

Dado o exposto, percebemos que para além das necessidades no campo religioso, o consumo excessivo no meio cristão-evangélico se desdobra por questões históricas, identitárias, mercadológicas, midiáticas e simbólicas. A partir da compra excessiva de produtos como bíblias diversificadas para públicos específicos, canecas, roupas e bolsas com frases bíblicas, indumentárias domésticas, materiais escolares, adesivos de veículos, chaveiros, jóias e bijuterias, entre outros, todos com ilustrações e ensinamentos cristãos, o consumidor cristão, buscando ser reconhecido como sujeito evangélico, contribui para a mercantilização daquilo que é considerado sagrado pelo grupo e para a criação de um sistema segregador, permeado por relações de exclusão dos indivíduos que não aderem a essas práticas dentro da própria comunidade.

Além disso, observou- se que, durante a pandemia, essa mercantilização foi intensificada por meio de compras online, pois as igrejas tiveram de se adaptar ao contexto pandêmico divulgando e vendendo produtos online durante as transmissões de cultos, e-commerce e redes sociais. 




Percebeu-se, contudo, que embora sejam desenvolvidos muitos estudos a respeito do tema, grande maioria deles são realizados a partir de um enfoque maior na doutrina neopentecostal, como tratado por Silva (2018) e Lima e Trasferetti (2007). Entretanto, a partir das vivências das autoras deste trabalho no meio evangélico, percebe-se a necessidade de estudos aprofundados sobre o tema também em organizações estruturais de bases tradicionais e pentecostais que se diferem nos ensinamentos pregados nas igrejas neopentecostais no que se refere às práticas de consumo analisadas nos artigos e livros utilizados como base para este trabalho.

\section{REFERÊNCIAS}

46\% dos brasileiros fizeram mais compras online na pandemia, indica Mastercard. ECBR, 2020. Disponível em: <https://www.ecommercebrasil.com.br/noticias/brasileiros-comprasonline-pandemia-coronavirus/>. Acesso em: 10 mar. 2021

$50 \%$ dos brasileiros são católicos, $31 \%$, evangélicos e $10 \%$ não têm religião, diz Datafolha. G1, 2020. Disponível em:

<https://g1.globo.com/politica/noticia/2020/01/13/50percent-dos-brasileiros-sao-catolicos31percent-evangelicos-e-10percent-nao-tem-religiao-diz-datafolha.ghtml>. Acesso em: 10 de abril de 2021.

ALVES, André de Andrade; BRITO, Janaina Viana Silva. Impactos do Novo Corona Vírus/COVID-19 no mercado de e-commerce no Brasil. Revista Innovare, Bahia, 30. edição, Jul - Dez, 2020.

CENSO 2010: número de católicos cai e aumenta o de evangélicos, espíritas e sem religião. Agência IBGE, 2012. Disponível em:

<https://agenciadenoticias.ibge.gov.br/agencia-sala-de-imprensa/2013-agencia-denoticias/releases/14244-asi-censo-2010-numero-de-catolicos-cai-e-aumenta-o-deevangelicos-espiritas-e-sem-religiao>. Acesso em: 10 mar. 2021.

LEMOS, Carolyne Santos. Teologia da prosperidade e sua expansão pelo mundo. Espaço Teológico, v. 11, n. 20, p. 80-96, jul./dez. 2017. Disponível em:

<https://revistas.pucsp.br/reveleteo/article/viewFile/35992/24781>. Acesso em: 22 out. 2019.

LINDBERG, Carter. História da reforma. Rio de Janeiro: Thomas Nelson Brasil, 2017.

LIMA, Maria Érica de Oliveira; TRASFERETTI, José. O cenário religioso de bens simbólicos: da produção ao consumo. Comunicação \& Inovação, São Caetano do Sul, v. 


\section{Criseng

8, n. 15, p. 48-56, jul./dez. 2007.

MORAIS, Edson Elias de. Religiosidade neopentecostal e o consumo de bens simbólicos. 90 f. Trabalho de Conclusão de Curso (Graduação em Ciências Sociais) Universidade Estadual de Londrina, Londrina, 2012.

PAEGLE, Eduardo Guilherme de Moura. A indústria cultural evangélica. In: Simpósio Nacional de História, 26., 2011, São Paulo. Anais [...]. São Paulo: ANPUH, 2011. p. 1-11. Disponível em:

<http://www.snh2011.anpuh.org/resources/anais/14/1300856723_ARQUIVO_artigoanpuh 2011usp21mar2011(2).pdf>. Acesso em: 21 out. 2019.

REFKALEFSKY, Eduardo; PATRIOTA, Karla Regina Macena Pereira; ROCHA, Maria da Penha Nunes da. Comunicação, Marketing e Religião: o mercado da fé no Brasil. In: Congresso Brasileiro de Ciências da Comunicação, 29., 2006, Brasília. Anais Intercom. Brasília: Unb, 2006. p. 1-13.

SILVA, Ana Beatriz Barbosa. Mentes consumistas: do consumismo à compulsão por compras. São Paulo: Globo, 2014.

SILVA, Déborah Pereira da. Consumo, comunicação e religião. São Paulo: UNINOVE, 2018.

SILVA, Tomaz Tadeu da (Org). Identidade e diferença: a perspectiva dos estudos culturais. 15. ed. Petrópolis: Vozes, 2014.

WEBER, Max. A ética protestante e o "espírito" do capitalismo. São Paulo: Companhia das Letras, 2004.

WOODWARD, Kathryn. Identidade e Diferença: uma introdução teórica e conceitual. In: SILVA, Tomaz Tadeu da (Org.). Identidade e Diferença: a perspectiva dos estudos culturais. Petrópolis, RJ: Vozes, 2014. p. 7-72. 